\title{
Mechanical and physical properties of aluminium-silicon (Al-Si) casting alloys reinforced by Zinc Oxide (ZnO)
}

\author{
Poppy Puspitasari ${ }^{1,2^{*}}$, Okky Rachmadilla Soepriyanto $^{3}$, and Muhammad Ilman Nur \\ Sasongko ${ }^{4}$, Johan Wayan Dika $^{4}$ and Andoko ${ }^{1}$ \\ ${ }^{1}$ Department of Mechanical Engineering, Faculty of Engineering, State University of Malang, 65145 \\ Malang, Indonesia \\ ${ }^{2}$ Center of Advanced Materials, State University of Malang, 65145 Malang, Indonesia \\ ${ }^{3}$ Department of Mechanical Engineering, Bachelor Program, State University of Malang, 65145 \\ Malang, Indonesia \\ ${ }^{4}$ Department of Mechanical Engineering, Postgraduate Program, State University of Malang, 65145 \\ Malang, Indonesia
}

\begin{abstract}
This study aimed to enhance the properties of aluminiumsilicon (Al-Si) alloys by adding zinc oxide as a reinforcing material. This study was a type of pre-experimental design called the one-shot case study, in which sample groups subjects were given treatments and then observed. The steps included melting the aluminium-silicon in a furnace at $900^{\circ} \mathrm{C}$, adding a certain amount of zinc oxide $(0.05 \%, 0.1 \%$, or $0.2 \%)$, stirring the mixture for 1 minute, and pouring it into a permanent mould. Results showed that, among the three specimens, the specimen reinforced with $0.2 \%$ zinc oxide had the highest tensile strength of $23.9 \mathrm{~kg} / \mathrm{mm}^{2}$, the greatest hardness of $134.4 \mathrm{HV}$, and a flat surface with evenly distributed grains and more brittle fracture.
\end{abstract}

\section{Introduction}

The process of metal casting includes melting the metal, pouring it into a mould, and letting it cool and solidify [1]. Aluminium-silicon casting alloys are widely used in automotive and aircraft industries because of their excellent properties such as low density, high strength-to-weight ratio, high corrosion resistance, good impact resistance, good thermal conductivity, and high wear resistance [2]. The addition of certain elements, such as calcium, sodium, strontium, and antimony, to aluminium-silicon alloys gives a fine eutectic structure or finer fibrous form [3].

Zinc oxide $(\mathrm{ZnO})$ is a white powder that is insoluble in water. It is frequently used as an additive in various materials and products including rubbers, plastics, ceramics, glass, cement, lubricants, paints, ointments, adhesives, pigments, foods, batteries, and fire retardants; its utilisation as a casting material is still uncommon. Zinc oxide $(\mathrm{ZnO})$ is a

\footnotetext{
* Corresponding author: poppy@um.ac.id
} 
unique material that has semiconducting, piezoelectric, and pyroelectric properties. When employing a solid-vapour thermal sublimation method, nanocombs, nanorings, nanohelixes/nanosprings, nanobows, nanobelts, nanowires, and nanocages of $\mathrm{ZnO}$ have been synthesised under specific growth conditions. These unique nanostructures clearly show that, among all materials, $\mathrm{ZnO}$ presumably has the richest family of nanostructures, both in structures and properties [4]. Physically, $\mathrm{ZnO}$ occurs as a white powder and is referred to as zinc white. Zinc oxide is an amphoteric oxide and nearly insoluble in water and alcohol but easily soluble in acids. The mineral form of zinc oxide is red or yellow, not the usual white colour, because it contains impurities such as manganese (Mn) and other elements. The crystalline form of zinc oxide crystals is thermochromic, which makes the colour change from white to yellow when heated and vice versa when cooled [5]. Improved casting properties of Al-Si alloys are achieved by melting nano-sized particles [6]-[11].

The mechanical properties can be enhanced by controlling additional materials, alloying elements, compaction rates, heat treatment, and others [12]. Jabeera et al. [13] explained the effects of zinc oxide nanoparticles on the aluminium-zinc alloy anodes. They found that $\mathrm{ZnO}$ nanoparticles could activate the sacrificial anodes effectively and were suitable for reinforcing aluminium alloy anodes. The substantial improvement of the metallurgical properties of anodes occurred due to reinforcing the anodes with nanoparticles, resulting in a significant reduction in the value of self-corrosion. Shin et al. [14] studied the refining effect of aluminium alloy (A356) microstructures by conducting an exothermic chemical reaction called aluminothermic reaction on aluminium alloy (A356) and zinc oxide nanoparticles $(\mathrm{ZnO}, \sim 20 \mathrm{~nm}$ in size) and the results showed an improvement in mechanical properties. Qasim et al. [2] studied the effect of adding zinc oxide nanorods to aluminium casting and found that it improved the mechanical properties.

\section{Method}

This study was pre-experimental research involving sample groups given treatments and then observed. In this research, the addition of a different percentage of zinc oxide $(0.05 \%$, $0.1 \%$, and $0.2 \%$ ) to Al-Si as the base material was observed. The cast specimens composed of Al-Si and varying amounts of zinc oxide were analysed by tensile testing using a machine from Tokyo Testing Machine MFG, hardness testing using a Rockwell type hardness tester (CV 600A), and morphological observation using a metal microscope from Nikon and a camera for macro photography from Canon.

As the initial step of the experiment, scrap pistons as the primary casing material and zinc oxide as the reinforcing agent were prepared. The scrap pistons were melted in a furnace for about 3 hours, producing $1.5 \mathrm{~kg}$ molten aluminium. Zinc oxide was then added to the molten aluminium and mixed using a stirrer from Bosch [15]. The resulting mixture was poured into a permanent mould and then air-cooled. The next stage was shaping the casting pieces using a metal lathe (Magnum Tech FEL-1640 GCY) to obtain standard tensile test specimens [16]. Macro photographs of the specimens subjected to tensile testing were taken for fracture analysis. After tensile testing, the specimens were cut for hardness testing.

\section{Results and Discussion}

\subsection{Tensile Testing}

The tensile strength of a material can be determined by conducting a tensile test. The tensile testing also aims to identify other properties such as creep strength, elongation, cross- 
section reduction, and modulus of elasticity. During tensile testing, specimens were subjected to tensile loading until fracture occurred [1]. The test was performed based on the ASTM A370-16 standard [16]. The test results are presented in Figure 1

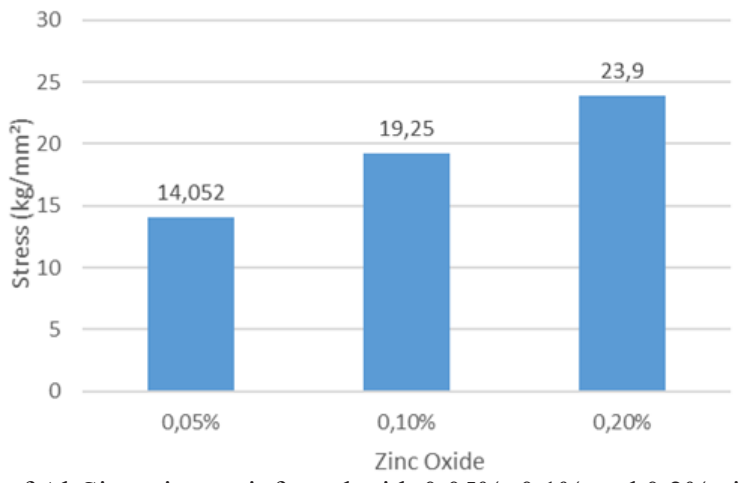

Fig. 1. Tensile strength of Al-Si castings reinforced with $0.05 \%, 0.1 \%$ and $0.2 \%$ zinc oxide

Figure 1 shows the improved tensile strengths of three aluminium silicon specimens reinforced with $0.05 \%, 0.1 \%$ and $0.2 \%$ zinc oxide. The Al-Si cast alloy reinforced with $0.1 \%, 0.05 \%$, and $0.2 \%$ zinc oxide had a tensile strength of $14.052 \mathrm{~kg} / \mathrm{mm}^{2}, 19.25 \mathrm{~kg} / \mathrm{mm}^{2}$, and $23.9 \mathrm{~kg} / \mathrm{mm}^{2}$, respectively. These results showed that the more the amount of zinc oxide, the higher the tensile strength.

Table 1. Comparison of the Tensile Strength of Al-Si Specimens Reinforced with Different Materials

\begin{tabular}{|c|c|c|c|}
\hline \multirow{2}{*}{ No. } & \multirow{2}{*}{ Reinforcement } & $\begin{array}{c}\text { Test Result } \\
\end{array}$ & \multirow{2}{*}{ Reference } \\
\hline & & Tensile Strength $\left(\mathrm{kg} / \mathrm{mm}^{2}\right)$ & \\
\hline 1 & $0.05 \%$ Zinc Oxide & 14.052 & \\
\hline 2 & $0.1 \%$ Zinc Oxide & 19.25 & \\
\hline 3 & $0.2 \%$ Zinc Oxide & 23.9 & \\
\hline 4 & $0.05 \%$ Eggshell & 12.24 & \multirow[t]{3}{*}{ Rizkiyan A (2018) } \\
\hline 5 & $0.1 \%$ Eggshell & 20.38 & \\
\hline 6 & $0.2 \%$ Eggshell & 16.86 & \\
\hline 7 & $0 \% \mathrm{Al}_{2} \mathrm{O}_{3}$ & 15.8 & \multirow[t]{14}{*}{ Iman $\mathrm{S}$ et al. (2015) } \\
\hline 8 & $1 \% \mathrm{Al}_{2} \mathrm{O}_{3}$ & 17.3 & \\
\hline 9 & $2 \% \mathrm{Al}_{2} \mathrm{O}_{3}$ & 19.8 & \\
\hline 10 & $4 \% \mathrm{Al}_{2} \mathrm{O}_{3}$ & 16.6 & \\
\hline 11 & $0 \% \mathrm{TiO}_{2}$ & 15.8 & \\
\hline 12 & $1 \% \mathrm{TiO}_{2}$ & 16.1 & \\
\hline 13 & $2 \% \mathrm{TiO}_{2}$ & 16.7 & \\
\hline 14 & $3 \% \mathrm{TiO}_{2}$ & 18.8 & \\
\hline 15 & $5 \% \mathrm{TiO}_{2}$ & 16.6 & \\
\hline 16 & $0 \% \mathrm{ZrO}_{2}$ & 15.8 & \\
\hline 17 & $1 \% \mathrm{ZrO}_{2}$ & 16.3 & \\
\hline 18 & $2 \% \mathrm{ZrO}_{2}$ & 17 & \\
\hline 19 & $3 \% \mathrm{ZrO}_{2}$ & 18.1 & \\
\hline 20 & $5 \% \mathrm{ZrO}_{2}$ & 16.7 & \\
\hline
\end{tabular}

As shown in Table 1, the addition of zinc oxide as a reinforcement could result in greater tensile strength than the use of $\mathrm{Al}_{2} \mathrm{O}_{3}, \mathrm{TiO}_{2}$ and $\mathrm{ZrO}_{2}$ nanoparticles. Though smaller 
in amount, zinc oxide could generate castings with a tensile strength exceeding the specimens reinforced with $\mathrm{Al}_{2} \mathrm{O}_{3}, \mathrm{TiO}_{2}$ and $\mathrm{ZrO}_{2}$ nanoparticles [7]. Compared to the use of $0.05 \%, 0.1 \%, 0.2 \%$ eggshell [17], still the addition of $0.2 \%$ zinc oxide could produce a higher tensile strength.

\subsection{Hardness Testing}

A three-point test was performed on each specimen. The results of hardness testing are shown in Figure 2.

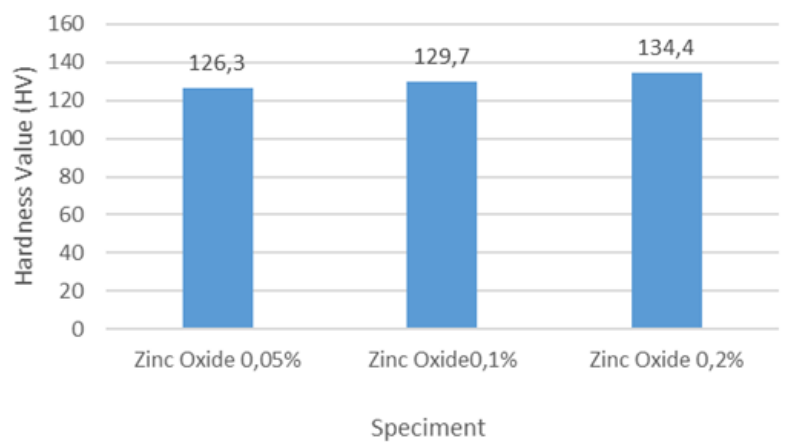

Fig. 2. Hardness of Al-Si castings reinforced with $0.05 \%, 0.1 \%$ and $0.2 \%$ zinc oxide

The results showed a notable difference in the hardness value of the three specimens (reinforced with $0.1 \%, 0.05 \%$, and $0.2 \%$ zinc oxide). The addition of $0.05 \%, 0.1 \%$, and $0.2 \%$ zinc oxide resulted in a casting product with a hardness value of $126.3 \mathrm{HV}, 129.7 \mathrm{HV}$, and $134.4 \mathrm{HV}$, respectively. In other words, the more the amount of zinc oxide, the higher the hardness value.

Table 2. Comparison of the Hardness of Al-Si Specimens Reinforced with Different Materials

\begin{tabular}{|c|l|l|l|}
\hline \multirow{2}{*}{ No. } & \multicolumn{1}{|c|}{ Reinforcement } & \multicolumn{1}{|c|}{ Test Result } & \multirow{2}{*}{ Reference } \\
\cline { 2 - 3 } & & \multicolumn{1}{|c|}{ Hardness (HV) } & \multirow{2}{*}{ Qasim et al. (2017) } \\
\hline 2 & $0.05 \%$ Zinc Oxide & 126.3 & \\
\hline 3 & $0.1 \%$ Zinc Oxide & 129.7 & \\
\hline 4 & Without Zinc Oxide Nanorods & 134.4 & \\
\hline 5 & $0.05 \%$ Zinc Oxide Nanorods & 78.3 & \multirow{2}{*}{ Iman S et al. (2015) } \\
\hline 6 & $0.1 \%$ Zinc Oxide Nanorods & 78.6 & \\
\hline 7 & $0.2 \% \mathrm{Zinc}_{\mathrm{n}}$ Oxide Nanorods & 79.2 & \\
\hline 8 & $0 \% \mathrm{Al}_{2} \mathrm{O}_{3}$ & 80.6 & \\
\hline 9 & $1 \% \mathrm{Al}_{2} \mathrm{O}_{3}$ & 103 & \\
\hline 10 & $2 \% \mathrm{Al}_{2} \mathrm{O}_{3}$ & 108 & \\
\hline 11 & $4 \% \mathrm{Al}_{2} \mathrm{O}_{3}$ & 130 & \\
\hline 12 & $0 \% \mathrm{TiO}_{2}$ & 132 & \\
\hline 13 & $1 \% \mathrm{TiO}_{2}$ & 103 & \\
\hline 14 & $2 \% \mathrm{TiO}_{2}$ & 114 & \\
\hline 15 & $3 \% \mathrm{TiO}_{2}$ & 130 & \\
\hline 16 & $5 \% \mathrm{TiO}_{2}$ & 141 & \\
\hline 17 & $0 \% \mathrm{ZrO}_{2}$ & 92 & \\
\hline 18 & $1 \% \mathrm{ZrO}_{2}$ & 103 & \\
\hline
\end{tabular}




\begin{tabular}{|l|l|l|l|}
\hline 19 & $2 \% \mathrm{ZrO}_{2}$ & 137 & \multirow{2}{*}{} \\
\cline { 1 - 3 } 20 & $3 \% \mathrm{ZrO}_{2}$ & 147 & \\
\hline 21 & $5 \% \mathrm{ZrO}_{2}$ & 101 & \\
\hline
\end{tabular}

Table 2 shows that the specimens reinforced with $0.05 \%, 0.1 \%$, and $0.2 \%$ zinc powder had greater hardness values than those in the research conducted by Qasim et al. [2] and Iman $\mathrm{S}$ et al. [7]. The addition of $\mathrm{Al}_{2} \mathrm{O}_{3}, \mathrm{TiO}_{2}$ and $\mathrm{ZrO}_{2}$ generated more hardness but the amount of it was 5-20 times more than zinc oxide.

\subsection{Microstructure Observation}

Microstructure observation was performed at $881.7 x$ magnification. Prior to observation, the specimens were polished and etched in accordance with ASTM E407-99 standard [18]. The observation aimed to examine the particle size distribution of Al-Si specimens. The size, morphology, and distribution of microstructures affect mechanical properties [19]. The observed results show a uniform distribution of particles in $\mathrm{Al}-\mathrm{Si}$ alloys. The photomicrographs of specimens reinforced with varying amounts of zinc oxide are presented in Figure 3a-c.

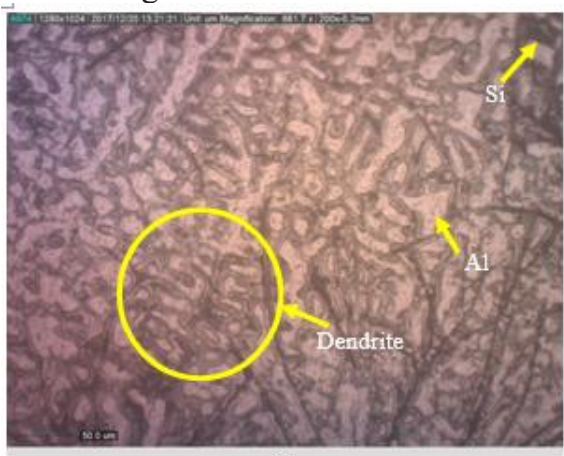

(a)

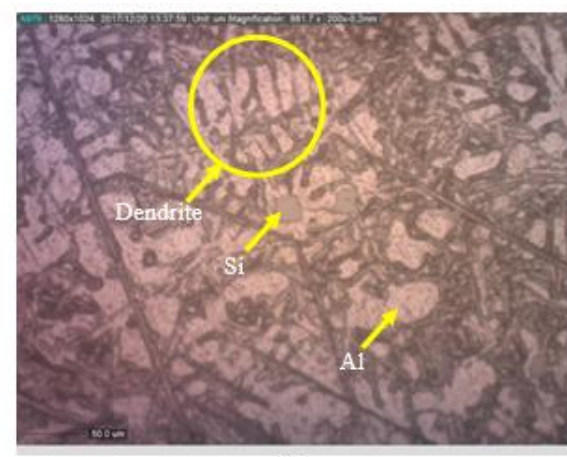

(b)

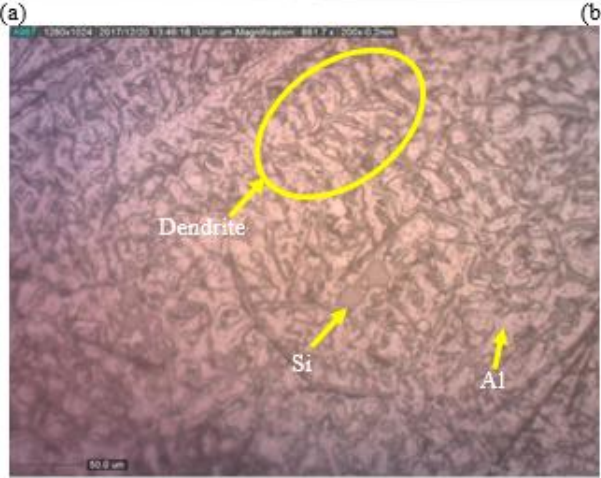

(c)

Fig. 3. Photomicrographs of tensile fracture surface: (a) Al-Si reinforced with $0.05 \%$ zinc oxide, (b) Al-Si reinforced with $0.1 \%$ zinc oxide, and (c) Al-Si reinforced with $0.2 \%$ zinc oxide

The microstructure of specimen reinforced with $0.05 \%, 0.1 \%$, and $0.2 \%$ zinc oxide is shown in Figure $3 \mathrm{a}, 3 \mathrm{~b}$, and $3 \mathrm{c}$, respectively. Figure $3 \mathrm{a}$ shows a uniform grain size distribution with some dendrites [2], [7], [10]. Compared to Figure 3a, Figure 3b shows a smaller grain size but larger dendrite size; solidification occurred much faster in this specimen [2], [7], [10]. Figure 3c shows that the grains become smaller and denser, grain 
boundaries are more clearly visible, and the dendrite structure is smaller, and grains are distributed more evenly than the other specimens [2], [7], [10]

\subsection{Macrostructure Observation}

The results of tensile testing were captured up close using a macro photography camera.

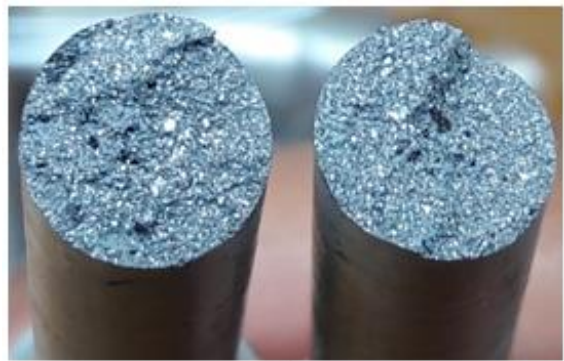

(a)

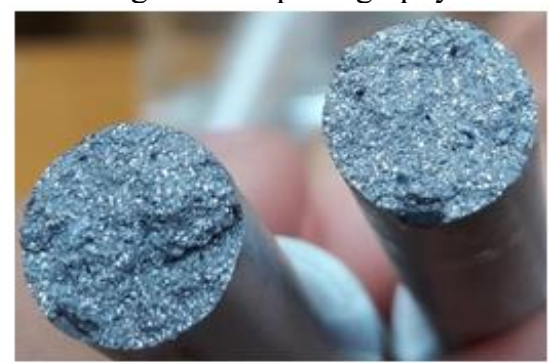

(b)

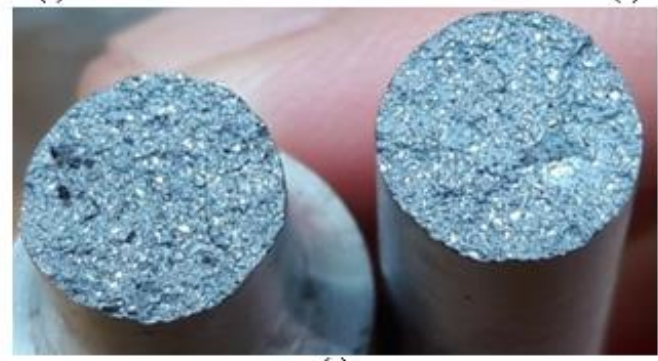

(c)

Fig. 4. Macro photographs of tensile fracture surface: (a) Al-Si reinforced with $0.05 \%$ zinc oxide, (b) Al-Si reinforced with $0.1 \%$ zinc oxide, and (c) Al-Si reinforced with $0.2 \%$ zinc oxide

Figure 4a shows a brittle fracture, i.e. a shiny, reflective, and flat surface [2], [7], [20], [21]. Figure $4 \mathrm{~b}$ shows a more brittle fracture, namely a flat surface that reflects light sharply and with no deformation during tensile testing; it occurred due to an increase in the hardness of casting material [2], [7], [20], [21]. Figure 4c shows the appearance of a more brittle fracture and an increase in tensile strength, compared to the other specimens; it shows a flat, highly reflective surface with no deformation as well as a material with high hardness and a fine-grained structure [2], [7], [20], [21].

\section{Conclusion}

The research results about Al-Si alloys reinforced with $0.05 \%, 0.01 \%$ and $0.2 \%$ zinc oxide have led to the following conclusions. Among the three specimens, the Al-Si casting reinforced with $0.2 \%$ zinc oxide had the highest tensile strength of $23.9 \mathrm{~kg} / \mathrm{mm}^{2}$ and the greatest hardness of $134.4 \mathrm{HV}$. This is supported by the macro image showing that the grains are smaller and denser, grain boundaries are more clearly visible, the dendrite structure is smaller, and grains are distributed more evenly than the other specimens; the smaller and denser the grains, the higher the ductility and strength. Photomicrography also showed that the addition of $0.2 \%$ zinc oxide resulted in a cast with a significant increase in tensile strength and more brittle fracture than those with the other concentrations; the image shows a flat, highly reflective surface with no deformation as well as a material with high hardness and a fine-grained structure. 
The authors acknowledge to State University of Malang for Hibah Penelitian PNBP UM 2018 with contract number 2.3.175/UN32.14/LT/2018.

\section{References}

1. R. A. Alberty, F. Daniels, and N. M. Surdia, Tat, 1-2, (1996)

2. Z. Qasim, M. Jabbar, and J. Hassan, J. Mater. Sci. Eng 4 1-8 (2017)

3. J. G. Kaufman and E. L. Rooy, Aluminum Alloy Castings: Properties, Processes, and Applications (2004)

4. Z. L. Wang, J. Phys. Condens. Matter, 16 829-858 (2004)

5. M. Kumar and S. S. Sahu, 1060402631 (2010)

6. I. El Mahallawi, Y. Shash, R. M. Rashad, M. H. Abdelaziz, J. Mayer, and A. Schwedt, Arab. J. Sci. Eng, 39, 6, 5171-5184 (2014)

7. I. El-Mahallawi, A. Shash, and A. Amer, Metals (Basel), 5, 2, 802-821 (2015)

8. I. El-Mahallawi, H. Abdelkader, L. Yousef, A. Amer, J. Mayer, and A. Schwedt, Mater. Sci. Eng. A, 556 76-87 (2012)

9. A. Mazahery, H. Abdizadeh, and H. R. Baharvandi, Mater. Sci. Eng. A, 518 61-64 (2009)

10. S. A. Sajjadi, H. R. Ezatpour, and M. Torabi Parizi, Mater. Des, 34 106-111 (2012)

11. H. Choi, H. Konishi, and X. Li, Mater. Sci. Eng. A, 541 159-165 (2012)

12. W. Zhang, Y. Liu, J. Yang, J. Dang, H. Xu, and Z. Du, Mater. Charact, 66 104-110 (2012)

13. B. Jabeera, T. S. Anirudhan, and S. M. A. Shibli, J. New Mater. Electrochem. Syst, 84 291-297 (2005)

14. J. H. Shin, J. H. Jeon, and D. H. Bae, Mater. Lett, 151 96-99 (2015)

15. U. K. Annigeri and G. B. Veeresh Kumar, Mater. Today Proc, 42 1140-1146 (2017)

16. ASTM, "E407 - 07 1-21 (2015)

17. A. S. Rizkiyan, P. Poppy, M. Putut, and R. S. Okky, (2017)

18. "Annual Book of Astm Standards."

19. J. Olofsson, I. L. Svensson, P. Lava, and D. Debruyne, Mater. Des, 56 755-762 (2014)

20. H. Tiwery, W. Hoziefa, and A. B. El-shabasy, (2018)

21. A. Y. Shash, A. E. Amer, and M. A. El-saeed, J. Nano Res, 38 1-8 (2016) 